\title{
Formula Development and Application of Wall Protection Slurry for Long-distance Horizontal Freezing Boreholes and Thorough Piles
}

\author{
JIANG Guojing ${ }^{1,2}$, ZHOU Xiaomin ${ }^{1}$, LI Fangzheng ${ }^{2}$, GAO Wei ${ }^{2}$, SUN Jianrong ${ }^{2}$, HAN Yufu ${ }^{2}$, YANG Zhigang ${ }^{2}$ \\ ${ }^{1}$ University of Science and Technology Beijing, Beijing 100083, China; \\ ${ }^{2}$ Beijing China Coal Mine Engineering Co., Ltd., Beijng 100013, China)
}

\begin{abstract}
Since complex barriers need to be passed through during the process of drilling long-distance horizontal freezing boreholes, the stability of the borehole wall at the soft and hard stratum interface is the key in controlling the deflection of the horizontal boreholes. The author puts forward to establishing the stability mechanical model of horizontal freezing borehole walls with fluid loss as the control index, starting from the stability mechanism of horizontal freezing boreholes and combined with the working conditions of horizontal freezing boreholes; selects two optimal fluid loss additives from the perspective of the molecular structure of bentonite materials, and determines the optimal formula by formulation optimization by virtue of orthogonal tests; applies the optimal formula into the long-distance pile and borehole penetration test, and validates the reliability of wall protection slurry formula materials for horizontal boreholes via comparing the water loss and soil erosion at the pile interface and analyzing the deflection rules, which is of certain value in engineering promotion and application.
\end{abstract}

\section{Introduction}

By taking the opportunity of subway construction, the underground space is faced with a great booming opportunity. Till the end of 2019, there are 40 mainland cities built with urban railway system, with the total operating mileage up to $6,290 \mathrm{~km}[1]$. The artificial freezing method, featured with excellent strength in reinforcing soil, wonderful water sealing performance, flexible design, minor impact to surroundings and other advantages, plays an irreplaceable role in the development of underground space[2]. Since the successful development of near-horizontal freezing technique in 1997, the ground freezing technique has been widely applied in the municipal works and subway freezing projects with water-rich soft ground[3]. In recent years, along with the pioneering networking development in the first-tier urban mass transit system, subway crossing projects are constantly mushrooming. Inevitably, newly-built lines may run through existing lines, as well as some operating stations. Due to the existence of the envelop enclosure and structures of the operating stations, it's impossible for shield tunneling machines to push forward as normal, and soil reinforcement and barrier clearance by applying the freezing method in the soft ground in advance is one of the safest and most effective methods to ensure the normal move-forward of shield tunneling machines.

Freezing borehole drilling is the key procedure of the construction of freezing method, and the forming accuracy of freezing boreholes is the key of successful connection of freezing boreholes. Considering the long distance of drilling freezing boreholes in the freezing crossing projects and a plurality of barriers (underground diaphragm walls, piles, latticed columns, etc.) frequently to be crossed during the crossing procedure, how to ensure the stability of soft soil at the soft and hard formation interface is the key of successful drilling. The normal way to ensure the stability of boreholes at the soft and hard formation interface is to apply the pipe-in-pipe method or slurry wall protection method. However, when crossing a plurality of barriers, pipe-in-pie method will result in more complex processes and increasing drilling costs. In terms of the drilling technique and economic feasibility, slurry wall protection method is one of the most effective methods.

Slurry plays a significant role in well clean-up/bore slagging, wall protection and cooling the drill during the well/borehole drilling, and its performance will directly influence the quality of protective walls and slagging effects, even determine the success or failure of the whole well/borehole drilling projects. Sun Jianrong ${ }^{[4]}$, based on the need of slurry stability during the sinking of well walls, introduced petroleum treatment agent FA367 to reinforce the stability of slurry in the coal mines. Tian Le ${ }^{[5]}$, combined with the segmentation of drilled boreholes of preliminary grouting projects at horizontal tunnel surrounding rock ground, designed the drilling fluid at different drilling stages. Bai Yang ${ }^{[6]}$ et al, 
targeting at the problems of shield tunnel machines in the integrated electric pipe rack on slurry film-forming at the sand layer and slurry film characteristics, developed a set of test unit for dynamic film-forming and permeability characteristics of slurry shield machines, and proceeded slurry penetration model test. Li Yufeng ${ }^{[7]}$ investigated and proposed the rule that during the construction of underground diaphragm walls, the larger the influence of slurry weight on the surrounding soil layers is, the larger the slurry weight is, the smaller the surge value of surrounding soil layers to the layer where the slurry is, and the smaller the settlement depth of the soil layer $(2 \mathrm{~m}$ underground) under the guide wall is. Sun Jinxin et al ${ }^{[8]}$, by virtue of slurry film-forming test unit, divided film formation at the slurry intrusion formation into two stages: slurry spray and slurry film formation. Liu Cheng et al ${ }^{[9]}$, by virtue of micro-analysis and model test of the formation and state classification of the slurry film, preliminarily established the macro and micro connection of the formation process of the slurry film, which made up for the deficiency of failing to take the dynamic formation of slurry film at the particle invasion soil layer by the traditional filtration theory and discrete element method. In conclusion, there are few researches on the formula of slurry materials and the stability of borehole walls for horizontal freezing pile and borehole penetration.

\section{Analysis of stability mechanism of walls of horizontal freezing boreholes}

Generally, horizontal freezing boreholes are constructed by drilling method. When it comes to barriers, coring of barriers should be carried out by using the coring bit, with the coring bit being pulled out after drilling the borehole, and re-putting the freezing pipe later. In case of piles or other complex barriers, it's easy for the bit to deviate when working at soft and hard formation interface, as a result, there are risks of the loss of soft soil, and even the instability of the bit. During the process of burying the freezing pipes, the borehole walls are in the state of under-pressure balance. Taking $40 \mathrm{~m}$ horizontal drilling as an example, the process of pulling and burying pipes may last for more than $9 \mathrm{~h}$. Under the state of under-pressure balance, the borehole wall should ensure the long-run stability. After analyzing the two working conditions of horizontal freezing boreholes, the author established the mechanical model of the stability of borehole walls during the drilling and after the formation of boreholes, based on the principle of water loss and permeability of slurry in formation during drilling.

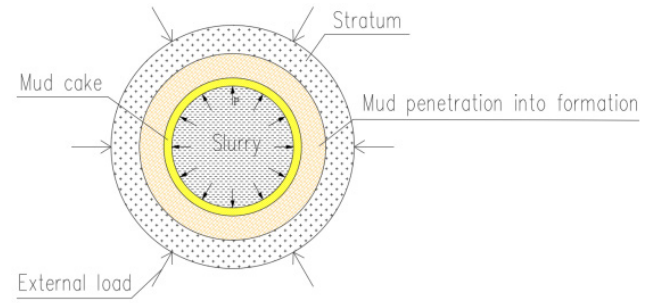

Fig.1 Mechanical model of slurry wall protection during horizontal freezing drilling

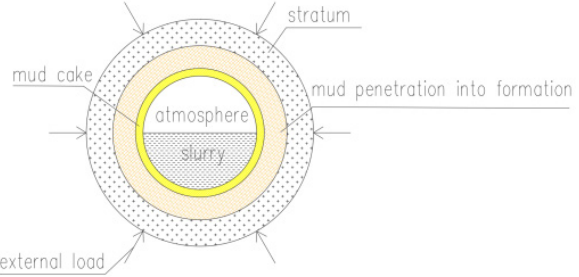

Fig.2 Mechanical model of slurry wall protection after horizontal freezing drilling

Based on the mechanical model for analyzing the stability of walls of horizontal freezing boreholes, the author proposed the idea of developing the slurry formula by taking the water loss of slurry as the control index. Usually, slurry slurry takes bentonite as raw materials for the base slurry. Bentonite is a kind of nonmetallic mineral taking the montmorillonite as the main mineral composition, with the molecular formula being $(\mathrm{Na}, \mathrm{Ca}), 0.33(\mathrm{Al}, \mathrm{Mg}) 2[\mathrm{Si} 4 \mathrm{O} 10](\mathrm{OH}) 2 \cdot \mathrm{nH} 2 \mathrm{O}$, and it is a crystal structure consisting of two silicon-oxygen tetrahedrons and a layer of aluminium oxygen octahedron at the ratio of 2:1, the structure of which is known as the "sandwich" structure of montmorillonite, and is distributed with charge in the structure. Therefore, in order to form thin dense and flexible slurry cakes by starting from the molecular structure and taking bentonite as the base slurry, the fluid loss additives shall contain active groups that can generate absorption reaction with charges, and then react with montmorillonite to form mesh-shaped flocculent structure via the macromolecular chain structure in the additives, thus forming a highly efficient wall protection slurry formula material.

\section{Scheme Design of Orthogonal Test}

In terms of the mechanism of slurry material forming the protective walls, fluid loss additives $\mathrm{B}$ and $\mathrm{C}$ prevail. After testing the bentonite A (as base slurry), the bentonite base slurry is confined within the scope of $2 \%-4 \%$, with that of fluid loss additive $\mathrm{B}$ being $0.1 \%$ - $0.3 \%$, and fluid loss additive $\mathrm{C}$ being $0.3 \%$ o- $0.5 \%$. The author designed and optimized the orthogonal test schemes by following the idea of "uniform dispersion and neat comparable" orthogonal test, without taking the interaction between elements into consideration. The three-factor and three-level orthogonal test can be taken, and $\mathrm{L}_{9}\left(3^{4}\right)$ orthogonal table can be adopted, with the factor level table as shown in Table 1.

Table 1 Factor level table

\begin{tabular}{|c|c|c|c|}
\hline level & bentoniteA (\%) & additiveB (\%o $)$ & additiveC (\%o $)$ \\
\hline 1 & 2.5 & 0.15 & 0.3 \\
\hline 2 & 3 & 0.2 & 0.4 \\
\hline 3 & 3.5 & 0.25 & 0.5 \\
\hline
\end{tabular}


Table 2 experiment scheme

\begin{tabular}{|c|c|c|c|}
\hline \multirow{2}{*}{ Test number } & \multicolumn{3}{|c|}{ factor } \\
\cline { 2 - 4 } & $\mathrm{A}$ & $\mathrm{B}$ & $\mathrm{C}$ \\
\hline 1 & 2.5 & 0.15 & 0.3 \\
\hline 2 & 2.5 & 0.2 & 0.4 \\
\hline 3 & 2.5 & 0.25 & 0.5 \\
\hline 4 & 3 & 0.15 & 0.4 \\
\hline 5 & 3 & 0.2 & 0.5 \\
\hline 6 & 3 & 0.25 & 0.3 \\
\hline 7 & 3.5 & 0.15 & 0.5 \\
\hline 8 & 3.5 & 0.2 & 0.3 \\
\hline 9 & 3.5 & 0.25 & 0.4 \\
\hline
\end{tabular}

\section{Analysis of the Orthogonal Test Results}

Table 3 Range analysis of orthogonal test results

\begin{tabular}{|c|c|c|c|c|}
\hline \multirow{2}{*}{ Test number } & \multicolumn{3}{|c|}{ factor } & \multirow{2}{*}{$\begin{array}{c}\text { Test result } \\
\text { water loss } \\
(\mathrm{ml})\end{array}$} \\
\hline & A & B & $\mathrm{C}$ & \\
\hline 1 & 2.5 & 0.15 & 0.3 & 5.6 \\
\hline 2 & 2.5 & 0.2 & 0.4 & 5.6 \\
\hline 3 & 2.5 & 0.25 & 0.5 & 7.6 \\
\hline 4 & 3 & 0.15 & 0.4 & 12 \\
\hline 5 & 3 & 0.2 & 0.5 & 12.5 \\
\hline 6 & 3 & 0.25 & 0.3 & 12 \\
\hline 7 & 3.5 & 0.15 & 0.5 & 12.5 \\
\hline 8 & 3.5 & 0.2 & 0.3 & 6 \\
\hline 9 & 3.5 & 0.25 & 0.4 & 10 \\
\hline K1 & 18.8 & 30.1 & 23.6 & \\
\hline $\mathrm{K} 2$ & 36.5 & 24.1 & 27.6 & \\
\hline $\mathrm{K} 3$ & 28.5 & 29.6 & 32.6 & \\
\hline$\overline{\mathrm{K}}_{1}$ & 6.3 & 10.0 & 7.9 & \\
\hline$\overline{\mathrm{K}}_{2}$ & 12.2 & 8.0 & 9.2 & \\
\hline $\mathrm{K}_{3}$ & 9.5 & 9.9 & 10.9 & \\
\hline Excellent level & $\mathrm{A}_{1}$ & $\mathrm{~B}_{2}$ & $\mathrm{C}_{1}$ & \\
\hline $\mathrm{R}$ & 5.9 & 2 & 3 & \\
\hline $\begin{array}{c}\text { Primary and } \\
\text { secondary order }\end{array}$ & & A C B & & \\
\hline
\end{tabular}

The optimal combination ratio is proved to be $A_{1} B_{2} C_{1}$ by applying the range analysis and taking the minimum water loss as the optimal level.

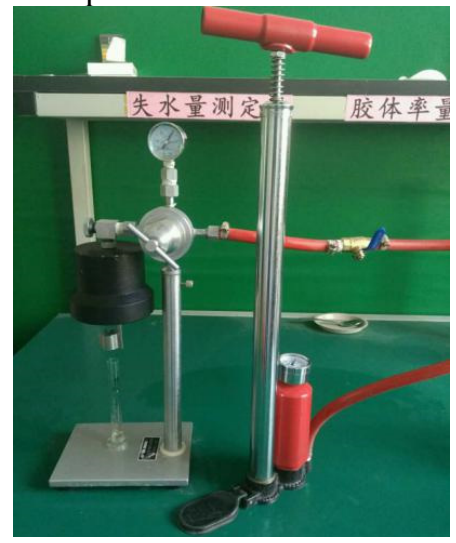

Fig.3 test of slurry water loss

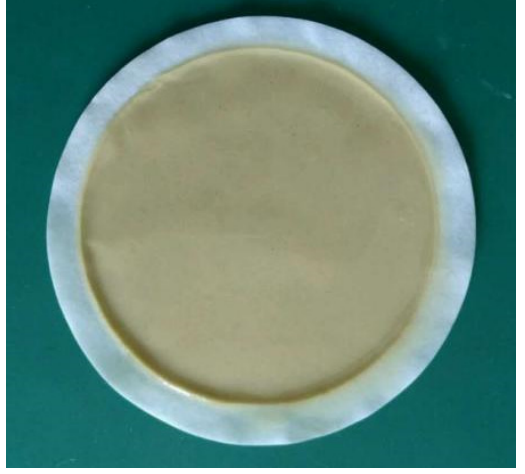

Fig.4 dense mud cake obtained after slurry water loss

\section{Application and Effect Evaluation}

The author adopted the slurry formula with the optimal ratio to prepare slurry slurry in the following steps: mix the bentonite and water, stir them in a mixing tank for 15-20 $\mathrm{min}$, then add additive 1 and additive 2 in turn, and pump the slurry with additives completely dissolved to the boreholes for continuous supply of slurry slurry; carry out the drill test by adopting the long-distance drill test platform, with the test platform, mainly consisting of clay, compacted layer by layer and the fully soaked with water. There were C50 concrete piles via cast-in-place concrete at the test platform. The slurry wall protection effect was tested by the drill test, especially when drilling into the concrete piles, and was checked by drilling and adjusting the thrust and torque of the drilling machine, checking the soil loss at the pile interface upon passing through the piles as well as the deviation of borehole track at the pile position.

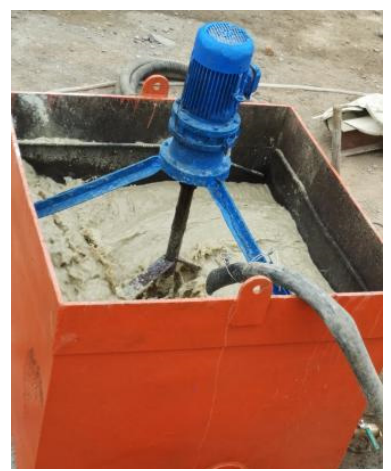

Fig.5 preparation of test slurry

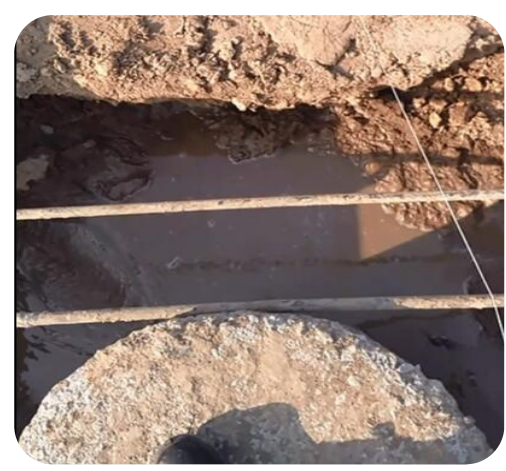




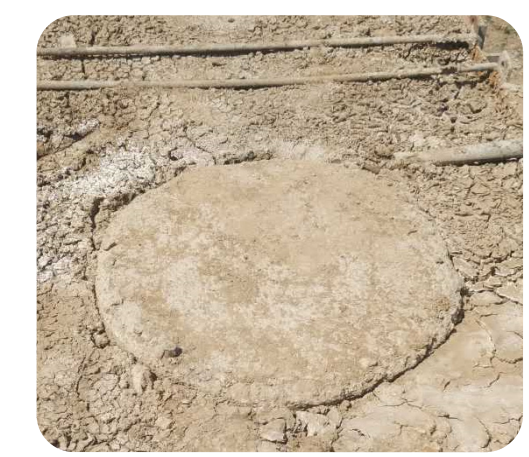

Fig.6 comparision between self-made slurry and new slurry materialin drilling to pile surface
The deflection of the formed boreholes can be test by light inclination surveying method upon the formation of boreholes, and the slurry wall protection effect of stabilizing the drill rod can be judged by observing the deflection of boreholes at the pile interface.

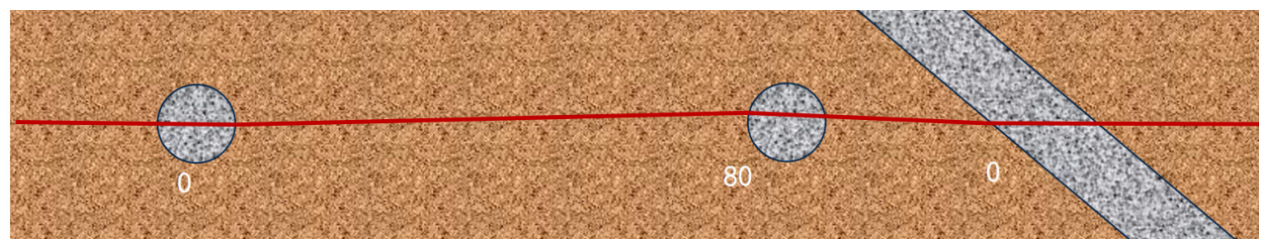

Fig.7 horizontal deviation of borehole

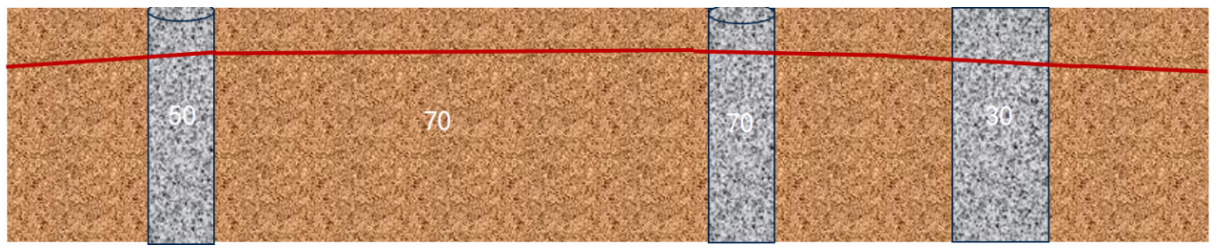

Fig.8 vertical deviation of borehole

Based on the analysis of horizontal and vertical deflection and borehole deflection curve at the pile interface, there was no significant deflection from the borehole to the pile interface in both horizontal and vertical direction. According to the test, the slurry wall protection can effectively stabilize the borehole wall at the pile interface, ensure the stability of drill rod, and the slurry wall protection effects were quite reliable.

\section{Conclusion}

The author puts forward to establishing the mechanical model of horizontal freezing borehole wall stability with fluid loss as the control index, starting from the working conditions of horizontal freezing boreholes; selects two optimal additives that can reduce the fluid loss of slurry from the perspective of the molecular structure of bentonite. The following points were summarized by designing the orthogonal test, analyzing the test results and proceeding industrial test:

1. According to the analysis of molecular structure of bentonite, the active groups in additive $\mathrm{A}$ and additive $\mathrm{B}$ can generate absorption reaction with charges in the "sandwich" structure of montmorillonite, and the macromolecular chain structure in the additives can react with montmorillonite's interlayers to form mesh-shaped flocculent structure, thus forming the effect of de-filtration.

2. According to the analysis of orthogonal test and extreme difference, the author prepared the optimal slurry formula materials, with the optimal combination ratio of efficient wall protection slurry materials being $\mathrm{A}_{1} \mathrm{~B}_{2} \mathrm{C}_{1}$.

3. According to the inspection of wall protection effects via industrial tests and analysis of borehole deflection track at the pile interface, the efficient wall protection slurry materials can stabilize the borehole walls at the soft and hard formation interface, then stabilize the drill rod, and achieve the purpose of preventing the deflection at the soft and hard formation interface.

4. The developed slurry formula materials are featured with small water loss, small weight, and such materials, by taking the water loss as the control index, can fulfill the performance of stabilizing the horizontal freeing boreholes after passing through the piles and drilling boreholes. As a result, it is of certain value in engineering promotion and application.

\section{Fund program :}

Science and technology innovation project of Tiandi technology Co., Ltd (2018-TD-QN010); Science and technology innovation project of Tiandi technology Co., Ltd (2018-TD-ZD004).

\section{Introduction to the first author:}

JIANG Guojing (1987-), male, mainly engaged in 
freezing method and grouting method research and site management.

\section{References:}

1. FENG Aijun.Current Status and Prospect of Urban Rail Transit Technology Development in China[J]. Jiangsu Construction, 2020(03):1-3.

2. LI Fangzheng. Application and Prospect of Freezing Technology in Municipal Engineering[J]. Mine Construction Technology,2017,38(04):55-60+49.

3. ZHOU Xiaomin. Development of artificial ground freezing technology in Subway Tunnel Engineering[A]. China civil engineering society. Harmonious development of underground engineering construction and development-The 4th China International Symposium on Tunnel Engineering [C].China civil engineering society: China civil engineering society, 2009:7.

4. SUN Jianrong. Analysis of Research and Development Status Quo of Coal Mine Drilling Mud Technologies[J]. Coal Technology, 2014, 33 (08): 90-92.
5. TIAN Le.Drilling Fluid Design of Horizontal Roadway Surface Pre-grouting Project[J].Coal Technology,2014,33(05):114-115.

6. BAI Yang, JIANG Binsong, YANG Le, et al. Experimental study on film forming characteristics of Slurry for large diameter slurry shield of Sutong GIL power utility tunnel[J].Water Resources and Power,2020,38(09):184-187+108.

7. LI Yufeng. R esearch and application of groove wall stability and wall protection slurry for super deep diaphragm wall[J].Shanxi Architecture,2020,46(19):69-71.

8. SUN Jinxin, ZHONG Xiaochun, FU Wei, et al. Experimental Study on Effects of Different Cations on Stability of Slurry Within Slurry Shield[J]. Chinese Journal of Geotechnical Engineering, 2020, 42(08):1525-1531.

9. LIU Cheng, SUN Jun, YANG Ping, et al. Mesoscopic analysis and model test on formation process and state division of slurry membrane[J]. Chinese Journal of Geotechnical Engineering, 2014, 36(03): 435-442. 